\title{
Ethics and aims in psychotherapy: a contribution from Kant
}

\author{
John S Callender Royal Cornhill Hospital, Aberdeen
}

\begin{abstract}
Psychotherapy is an activity which takes many forms and which has many aims. The present paper argues that it can be viewed as a form of moral suasion. Kant's concepts of free will and ethics are described and these are then applied to the processes and outcome of psychotherapy. It is argued that his ideas, by linking rationality, free will and ethics into a single philosophical system, offer a valuable theoretical framework for thinking about aims and ethical issues in psychotherapy.

(Fournal of Medical Ethics 1998;24:274-278)
\end{abstract}

Keywords: Ethics; psychotherapy; Kant

\section{Introduction}

"The psychic phenomena in question are not like a cold or pneumonia, nor like general paralysis or a brain tumour, dementia praecox or epilepsy. They are still phenomena within the realm of freedom. A need for therapy here signifies acceptance of loss of freedom, though in fact freedom is still there and maintains its rights at the same time as it renounces them." 1

This quotation from Karl Jaspers encapsulates the principal difference between psychotherapy and other forms of treatment. The patient who seeks psychotherapy does not see him or herself as the passive victim of an illness outwith his control but usually as someone grappling with self-destructive emotions, thinking and behaviour over which he or she seeks control.

Loss of freedom is central to many of the problems and symptoms encountered by the psychotherapist. However, there is an intrinsic ambivalence in psychotherapy in relation to free will. The main aim of theory and research in psychology and psychotherapy is to bring human behaviour, feeling and thought into an explanatory, scientific paradigm. As the explanatory power of psychology advances, it may create an ever more deterministic view of human nature. The potential end result of such endeavour is summarised by B F Skinner, one of the founders of behavioural psychology, when he states: "It is the autonomous inner man who is abolished and that is a step forward."
There is also potential ambivalence in therapeutic setting. Although the patient seeks in increase in freedom, he may find himself in a restionship with his therapist in which power is unequally distributed. He may come to feel dependent on a therapist who seems omniscient and who is in a position to control the course the therapy. He might then be at risk of exploitgtion and harm, which sometimes repeats the trauma which led to his problems arising in the first place. ${ }^{3}$

Those who practise psychotherapy should he्ष户e a clear concept of freedom. The present paper describes Kant's concept of free will and the ethical system which arises from this. It argues frobn this that psychotherapy may be understood exercise in moral improvement and that Kand's thinking offers philosophical standards aga ist which psychotherapy may be judged.

\section{Kant, free will and ethics}

THE KANTIAN CONCEPT OF FREE WILL

Kant discusses the concept of free will in the s鹿ond part of the Critique of Pure Reason. In the Third Antinomy of Pure Reason, Kant firsily advances a thesis for the existence of free will a d then its antithesis that "There is no freedom; eج⿱乛龰 rything in the world takes place solely $\dot{g}$ n accordance with the laws of nature". ${ }^{4}$ If a capacity for freedom is to be demonstrated then thesis agd antithesis must be reconciled. Otherwise, possibility of freedom must be abandoned In favour of the laws of natural necessity which have the strength of being demonstrable by empirical enquiry. ${ }^{5}$

In Kant's resolution of the antinomy, he understands freedom as "the power of beginning a store spontaneously". A free act is one which is uncthditioned, which is not the effect of a prior cause. He then asks: "Is it a truly disjunctive proposition to say that every effect in the world must arjse either from nature or from freedom; or must क्षेe not say that in one and the same event, in differ relations, both can be found". ${ }^{7}$ This necessitafes looking at events from two standpoints. The first of these, Kant terms the "sensible world", which is 
the world as it appears to our perception. However, he also argues that the "presupposition of the absolute reality of appearances" is fallacious and that beyond this is the transcendent reality of an "intelligible world" of "things in themselves".

In human life, this intelligible world of the mind is not subject to the laws of cause and effect but rather to the laws of reason. The principal evidence that "reason has causality, or that we at least represent it to ourselves as having causality, is evident from the imperatives which in all matters we impose as rules upon our active powers". ${ }^{9}$ The capacity to say that something "ought" to happen, expresses a form of causality which does not exist in the natural world. We do not say that a circle ought to have certain properties, but rather set out to determine what these are. In contrast, "ought" expresses a possible action on the ground of a concept generated by reason. In this sense one is a subject, a creator of one's own world. If a man commits a crime, one might understand this as the effect of antecedent causes, such as poverty or lack of education but, despite this, maintain that he ought not to have done it and that his action is reprehensible and worthy of punishment. ${ }^{10}$ As a recent political slogan puts it, one may be "tough on crime and tough on the causes of crime"!

\section{KANTIAN ETHICS}

The development of an ethical system is the main subject matter of the Critique of Practical Reason ${ }^{11}$ and the Groundwork of the Metaphysic of Morals. ${ }^{5}$ In these works, Kant set out to provide rational justifications for fundamental moral principles.

Their central idea is the existence of moral imperatives founded on the principles of reason. These are universal and applicable to all rational beings in all circumstances, allowing of no exceptions. They are unconditional and override all other considerations such as the likelihood of personal gain or gratification of one's desires.

The central principle is the Categorical Imperative, which is first stated as: "Act only on that maxim through which you can at the same time will that it should become a universal law". ${ }^{12}$ The application of the principle of universality is formal rather than consequential. Maxims should be capable of application without becoming self-contradictory. ${ }^{13}$

A purely rational agent would be compelled by his rational nature to acknowledge the requirements of the Categorical Imperative. To do otherwise is to renounce a fundamentally human wellspring of motivation. In the Critique of Practical Reason, Kant argues that freedom has its origin in the awareness of the possibility of moral choice. ${ }^{14}$
It is important to emphasise that moral life as Kant conceptualises it is not simply a matter of obedience to rules or laws. One might obey from expectation of reward for obedience or punishment for disobedience. In this case action is not autonomous but rather is heteronomous or, in modern terminology, contingent on other factors. In contrast, the moral agent acts, not on the basis of rules imposed from without, but rather on the basis of acceptance of fundamental moral principles, derived from reason and "regarded neither as an object of inclination, nor as an object of fear". ${ }^{15}$ The position is summarised by Scruton who states: "The free agent, as soon as we examine the question, we see to be distinguished, not by his lack of constraint, but by the peculiar nature of the constraint which governs him. He is constrained by reason, in its reception of the moral law." 16

The nature of Kantian morality is developed in three further statements, The Formula of the End in Itself, The Formula of Autonomy and The Formula of the Kingdom of Ends. These again are based on rationality and universality of application.

As an end, Kant seeks for "something whose existence has in itself an absolute value, something which as an end in itself could be a ground for determinate laws ...". ${ }^{17} \mathrm{He}$ states that "man, and in general every rational being exists as an end in himself, not merely as a means for arbitrary use by this or that will ...". ${ }^{18}$ The Formula of the End in Itself is thus stated as: "Act in such a way that you always treat humanity, whether in your own person or in the person of any other, never simply as a means, but always at the same time as an end". ${ }^{19}$

The Formula of Autonomy states: "So act that your will can regard itself at the same time as making universal law through its maxims". ${ }^{20}$ This emphasises that moral laws are not simply to be followed, but are to be followed because they have been created by ourselves as rational beings. As Kant states of a rational being, "...it is precisely the fitness of his maxims to make universal law which marks him out as an end in himself". ${ }^{21}$

The Formula of the Kingdom of Ends is given as: "So act as if you were through your maxims a lawgiving member of a kingdom of ends". ${ }^{22}$ This bids the rational being to act as if he were part of a hypothetical, ideal society whose members are subject to laws based on reason. These laws are made and accepted by all members of such a society and bid them to treat themselves and others as ends. ${ }^{23}$

In summary, the following elements of Kant's philosophy are important for present purposes. Firstly, free will rests on the faculty of reason. Secondly, human life has to be viewed from the standpoint of that which can be perceived and which is subject to the laws of nature but also from 
that of the intelligible world of the mind, which cannot be observed and which is subject to the laws of reason. Thirdly, freedom becomes evident in our ability to conceive the world as it ought to be. The application of reason to moral behaviour leads to the creation of unconditional imperatives, which the moral agent is constrained by his rationality to accept. Finally, the aim of Kant's ethics is that individuals should treat themselves and others as ends in themselves with the ultimate aspiration being a society of free and mutuallyrespecting members.

We will now consider the application of these ideas in turn to psychotherapy.

\section{Applications to psychotherapy}

PSYCHOTHERAPY AND RATIONALITY

The purpose of the rational mind is to allow us to understand the world and ourselves. Psychotherapy should not be about the promotion of illusions about oneself, however comforting they may be or about the imposition of dogmatic theoretical constructs. Claims to promote understanding cannot be assured unless psychotherapeutic theory and outcomes can withstand externally verifiable tests of their validity. The scientific credibility of psychotherapy is a complex and controversial subject and it is not the purpose of this paper to discuss this. Psychoanalytical therapies have been criticised for many years for their unscientific theorising and their failure to demonstrate superior outcomes to placebo procedures. ${ }^{24}$ There are many ethical objections to ineffective therapy. If a main purpose of psychotherapy is to enhance freedom then this can only happen on the basis of a true understanding of oneself and the world. A therapy whose theory and outcomes do not rest on a firm foundation of knowledge cannot be assured of being ethical.

Many forms of therapy have as one of their aims, the relief of symptoms through improved self-understanding. Freud stated that the function of psychoanalysis "is, indeed, to strengthen the ego ... to widen its field of perception and enlarge its organisation so that it can appropriate fresh portions of the id. Where id was, there ego shall be". ${ }^{25}$ In one of the most widely-used forms of therapy, cognitive therapy, the central therapeutic tactic is to bring the power of the rational mind to bear on symptoms and problems. A patient will be asked to examine the ways in which he construes his world and to make links between these constructions and his emotional state. $\mathrm{He}$ will then be invited to reconsider and to generate alternative ways of understanding his life in the expectation that this will allow him to see himself and his prospects in a more positive light. Thera- peutic change depends principally on the culti甲ation of the powers of reason of the patient application of these to life problems.

Cognitive models of depression and other psychiatric disorders attempt to provide a cohe ent theory of causation and therapeutic change, which is open to external validation. As a resw $\mathrm{w} t$, cognitive therapy is now the most extensive researched psychological treatment in patie with depressive disorders. ${ }^{26}$

An idea of central importance to the present paper is that the rigorous application of rational principles to life leads on, ineluctably accordingto Kant, to an ethical stance in relation to oneself and others.

PSYCHOTHERAPY AND THE TWO STANDPOINTS Kant's position on the two standpoints has befn subjected to philosophical criticism. ${ }^{27}$ Neverthelesss, he points to a tension between freedom and caưsal necessity which is ever-present in psychotherapy. Gellner describes psychoanalysis as "an energycapturing system, and one of the important sourses of energy which it taps with great efficiency, is precisely the frictional heat generated by the rubbingoof authenticity against reducibility. This systeg. of ideas harnesses both our sense of heteronowag a dependence on forces we do not understan e end cannot control, and our hope that autono authenticity should be feasible". ${ }^{28}$

As described above, some proponents of beh ioural psychology have attempted to move avoy from the idea of the patient as autonomous, potentially autonomous, agent. This is reflectegin behaviour therapy, in which a component of behaviour is targeted for modification, usually the creation of a system of disincentives to the behaviour and rewards for carrying out alter tive, desired behaviour. Such "behavioural pógrammes" have been applied to various problems, such as the promotion of weight gain in Ge underweight patient with anorexia nervosa. ${ }^{29}$

Even if they are successful in their own terms, such treatments may be seen as degrading a d dehumanising by patients. A sense of autonomy is a fundamental part of the self-concept of indivi fistals and indeed the patient with an eating disorker may describe control of her body-weight as a fast redoubt of autonomy in a world which seems to $\$$ be outwith her control. ${ }^{30}$

While behaviour therapy has the advantages of clear-cut aims and measurable outcomes, it risks reducing the patient to the status of an object. कृo be ethical, behaviour therapy should be carraed out with the full cooperation and understandîfg of the patient, with the ultimate aim of promoting autonomy. If there is an element of duress, the 
behavioural approach risks depreciating the status of the patient as a rational, moral agent and subjecting him or her to new forms of control.

\section{PSYCHOTHERAPY AND MORAL IMPERATIVES}

According to Ryle "The central aim and value of psychotherapy ... is that of enlarging people's ability to live their lives by choice". ${ }^{31}$ However, a therapist may have to decide which choices are to be promoted and which are to be discouraged. A girl who has been sexually abused might choose to kill her abuser. Alternatively, she might feel so wretched that she chooses to mutilate herself or to take her own life. Therapists cannot encourage every possible choice and this entails making ethical judgments about patients' intentions and behaviour.

The first topic discussed in the Groundwork of the Metaphysic of Morals is that of good will. An agent acting out of good will, does good, not because it suits his purposes but rather out of a sense of duty. To behave in ways which are honourable and morally worthy is an important contribution to self-esteem - "... would he not still find in himself a source from which he might draw a worth far higher than any that a good-natured temperament can have?" ${ }^{32}$ The repair of damaged self-esteem is often a main purpose of psychotherapy and the promotion of moral behaviour may contribute to this.

Thoughts of suicide and a history of suicidal acts are commonly found in psychotherapy patients. The first application of the Categorical Imperative in the Groundwork of the Metaphysic of Morals is to suicide. Kant proposes that the maxim underlying the impulse to suicide is: "From self-love I make it my principle to shorten my life if it threatens more evil than it promises pleasure". ${ }^{33} \mathrm{He}$ states that the function of self-love is to stimulate the furtherance of life and that if this feeling were to destroy life, then it would contradict itself and "could not subsist as a system of nature". ${ }^{34}$ It is doubtful whether Kant describes the demoralised state of mind of the suicidally depressed patient. Nevertheless, the attempt to formulate a formal principle against suicide is of interest and Kant returns to this theme more convincingly in The Formula of the End in Itself.

\section{AIMS OF PSYCHOTHERAPY AND THE END IN ITSELF}

The Formula of the End in Itself enjoins us to treat humanity, both in ourselves and in others, never just as a means, but always at the same time as an end. Thus, to behave in ways which are destructive to oneself or others is not only distressing and disturbing, but also ethically inadmissible. To end one's life when it no longer seems tolerable is to regard life as the means to the end of a state of contentment. Kant argues that it is morally wrong to treat one's life as a means to an end rather than an end in itself. ${ }^{35}$ Writing of suicide in the Metaphysic of Morals he states: "To destroy the subject of morality in one's own person is to root out the existence of morality itself from the world, so far as this is in one's power; and yet morality is an end in itself". ${ }^{36}$ Although papers have appeared in the psychotherapy literature examining the arguments for "rational suicide", ${ }^{37}$ this can have no place in Kant's moral system.

Kant also argues that, while we have a "perfect" duty, allowing of no exceptions, not to use humanity in ourselves and others solely as a means to an end, we also have an "imperfect" duty actively to promote the idea of the end in itself. With regard to ourselves, we should increase our "capacities for greater perfection... in our person". ${ }^{38}$ With regard to others, everyone should endeavour "to further the ends of others. For the ends of a subject who is an end in himself, must, if this conception is to have its full effect on me, be also, as far as possible, my ends". ${ }^{38}$

In the case of many, if not most, patients who present for psychotherapy, their problems have their origin in the traumatic experience of having been used as the means to the end of another. A stark example of this is the child who has been used for the sexual gratification of an adult, but lesser degrees of exploitation and oppression can also be psychologically damaging. Other patients may have been damaged by upbringings characterised by emotional deprivation or abuse, or in which there is a failure in other ways on the part of their parents positively to promote them as ends in themselves.

The end results of such experiences may at worst be an unstable and fragmented sense of self, as is found in patients with borderline and multiple personality disorders. There will usually be varying combinations and degrees of depression, anxiety, low self-esteem and suicidality. Patients such as these lack a sense of self-worth and are vulnerable to domination and exploitation by others. In short, they lack a self-concept of being ends in themselves.

One observation from psychotherapy outcome studies is that most therapies are seen to be equally efficacious. ${ }^{39} \mathrm{~A}$ possible reason for this may be that it is the common, non-specific elements of psychotherapy which are of therapeutic value. ${ }^{40}$ Carl Rogers's triad of "genuineness, empathy and unconditional positive regard" is widely accepted as describing the core constituents of successful therapy. ${ }^{41}$ It might be argued that this offers the patient, perhaps for the first 
time in his life, the experience of being actively promoted as an end in himself. One aim of therapy should be for the patient to acquire a self concept of being an end in himself.

The Formula of the End in Itself also enjoins the agent not to treat others simply as a means. Psychotherapy should not only be aimed at improvement in the patient, but should also help him towards living in relationships of mutual respect with his fellow human beings.

\section{Conclusions}

In conclusion, it is argued that Kant's philosophy offers a theoretical framework for psychotherapy by its linking of free will, rationality and ethics into a single philosophical system. Psychotherapy which is consistent with this system would have the following characteristics:

1)It would aim to promote self-understanding and autonomy. The validity of such understanding can only be assured when therapy has a firm foundation of knowledge with regard to theory and therapeutic outcomes.

2) Patients should never only be reduced to the status of objects or behaviour-to-be-modified, but should at the same time be regarded as autonomous, or potentially autonomous, agents.

3)Free will is promoted by cultivation of the patient's powers of reason and bringing these to bear on his problems.

4)Free will, in Kant's view, arises from the ability to make moral choices. The freedom which is promoted is not freedom from restraint but rather freedom to live according to one's own, rational principles. Some principles have the status of categorical moral imperatives, to be followed by all rational beings.

5)The aims of therapy should include the cessation of self-destructiveness and destructive behaviour directed towards others and the active promotion of humanity, both in the patient and in his relations with others, as an end in itself. Suicide is ethically prohibited in all circumstances.

\section{Acknowledgements}

Dr Nigel Dower, Department of Philosophy, University of Aberdeen provided very helpful comments on a first draft of the paper. Thanks are due to Mrs Kathleen Proctor for careful preparation of the paper. fohn S Callender MD, MRCPsych, is Consult $\stackrel{\mathbb{D}}{\text { (n) }}$ Psychiatrist at the Royal Cornhill Hospital, Aberde舆.

\section{References}

1 Jaspers K. The nature of psychotherapy. Manchester: Mancheter University Press, 1964: 22.

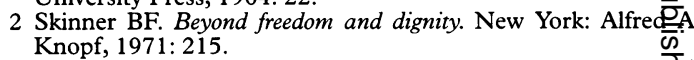

3 Dawson EM. Professional misconduct in psychiatry: sex behaviour with patients. A report of recent New South Wabes findings. Australian and New Zealand fournal of Psychiory 1994;28:197-204.

4 Kant I. Critique of pure reason. Translated by Kemp Smith $\mathrm{N} \overrightarrow{\mathrm{G}} \mathrm{s}$ Immanuel Kant's critique of pure reason. London: Macmillan, 1934: 473(page nos refer to 2nd ed).

5 Kant I. Groundwork of the metaphysic of morals. In: Paton $\mathbf{E P}$. The moral law. London: Routledge, 1991:113-115 (page ్ㅡㅇs refer to 2nd ed of Groundwork).

6 See reference 4:561.

7 See reference $4: 564$

8 See reference 4:564-5.

9 See reference $4: 575$.

10 See reference $4: 575-85$.

11 Kant I Critique of practical reason [3rd ed]. Translated by Whit Beck L. New York: Macmillan, 1993.

12 See reference 5: 51-52.

13 See reference 5: 52-9.

14 See reference $11: 28-30$.

15 See reference 5:16.

16 Scruton R. $A$ short history of modern philosophy [2nd London: Routledge, 1995:149.

17 See reference 5:64.

18 See reference 5:64-5.

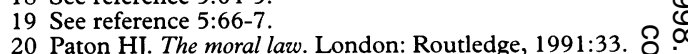

21 See reference 5:83.

22 See reference $20: 34$.

23 See reference 5:74-7.

24 Prioleau L, Murdock M, Brody N. An analysis of p\$rctotherapy versus placebo studies. The Behavioral and B Sciences $1983 ; 6 ; 275-310$.

25 Freud S. New introductory lectures on psychoanalysis. Harmor国sworth: Pelican Books, 1973: 112.

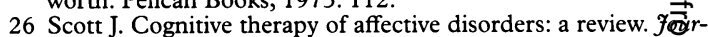
nal of Affective Disorders 1996;37: 1-11.

27 Honderich T. $A$ theory of determination. The mind, neuroscienee, and life-hopes. Oxford: Clarendon Press, 1988: 460-3.

28 Gellner E. The psychoanalytic movement. London: Paladin Grafton Books, 1985: 123.

29 Agras WS. Behaviour therapy. In: Kaplan HI, Sadock BJ, Comprehensive textbook of psychiatry [6th ed.]. BaltimPre: Williams and Wilkins, 1995:1788-1807.

30 An anorexic patient. Which option would you take? Brits Medical fournal 1995;311:635-6.

31 Ryle A. Psychotherapy: a cognitive integration of theory Qnd practice. London: Academic Press 1982: 3.

32 See reference 5:11.

33 See reference $5: 53$.

34 See reference 5:54.

35 See reference 5:67.

36 Kant I. The metaphysic of morals. Translated by Gregor M The doctrine of virtue, New York: Harper Torchbooks, 1964:185.

37 Siegel K. Psychosocial Aspects of Rational Suicide. Ameritan fournal of Psychotherapy 1986;40:405-18.

38 See reference 5:69.

39 Stiles WB, Shapiro DA, Elliot R. Are all psychothera@ies equivalent? American Psychologist 1985;41: 165-80.

40 Smith ML, Glass GV, Miller TI. The benefits of psychotherkpy. Baltimore, Maryland: Johns Hopkins University Press, $1 \notin 0$ :

41 Rogers CR. The necessary and sufficient conditions of therapeutic personality change. Fournal of Consulting Psychotogy 1957;21:95-103. 